\title{
Method for environmental impact assessment of human-induced small-medium activities: the case study of wood biomass supply chain
}

\author{
Marina Clerico ${ }^{1, *}$, Matteo Bo $^{1}$, and Federica Pognant ${ }^{1}$ \\ ${ }^{1}$ Politecnico di Torino - DIATI, Corso Duca degli Abruzzi 24, Torino 10129, Italy
}

\begin{abstract}
Climate change evolution, joined by other environmental issues, will lead in the coming years to a rapid introduction of new actions and technologies. They will have to resolve, in the different economic sectors, one or more aspects of the current unsustainability. The relevant risk is that, in urgent conditions where the unreleased practices will be proposed, the assessment of their environmental impact will remain limited to their specific field/sector. Therefore, the evaluation would not be extended to any wide-ranging environmental effects. Without an accurate assessment it would be impossible to determine whether the solution was more damaging and burdensome to the environment than the initial problem. Small-medium anthropic activities do not possess, from the economic point of view, the means and the duty to achieve an impact analysis ad hoc. This work aims to describe an analysis methodology developed for the environmental impact assessment of Small-Medium Enterprises. It is both exhaustive and easily applicable to small work activities and processes. This methodology is aimed both at business managers and at local authorities. The identified method of analysis allows an exhaustive evaluation of the whole forest energy chain and the identification of technical choice with less impact on the environment.
\end{abstract}

\section{Introduction}

Climate change evolution, joined by other environmental issues, will lead in the coming years to a rapid introduction of new actions and technologies. They will have to resolve, in the different economic sectors, one or more aspects of the current unsustainability. The relevant risk is that, in urgent conditions where the unreleased practices will be proposed, the assessment of their environmental impact will remain limited to their specific field/sector. Therefore, the evaluation would not be extended to any wide-ranging environmental effects. Without an accurate assessment, it would be impossible to determine whether the solution was more damaging and burdensome to the environment than the initial problem.

For important actions the method for the Environmental Impact Assessment (EIA) are defined by the law[1] and strictly controlled. This method is very unspecific and targeted to reduce and prevent environmental impacts on a large scale. Thus, it does not take into account, specifically, the Small-Medium Enterprises (SMEs) [2]. Small-medium anthropic activities do not possess, from the economic point of view, the means and the duty to achieve an impact analysis ad hoc. Less financial resources make difficult the identification and use of the Best Available Technologies (BAT) and suitable work procedures to decrease risks for the inhabitants of the territory and the environment [3]. However the availability of a simplified and guided framework would make the compulsory assessment technically and economically feasible. There is, therefore, the need to adapt, simplify and standardise the environmental impact assessment methods for a faster and easier implementation, while simultaneously allowing a comprehensive evaluation of the environmental impacts.

The objective of this study is to present a simplified analysis methodology for a correct and rapid analysis of small plants or productive activities and the identification of their impact on the surrounding territory. This method was applied to both existing activities and plants, both in the design and prototype phases. It has been validated through the application of standardised methodologies, such as measurements and application of dispersion models for estimating the environmental impacts.

The case study chosen to test the proposed method is the wood biomass supply chain from the wood to the energy conversion. Given the strong incentivisation in the last years, the use of wood biomass as renewable source of energy and heat is steadily growing. This is due to the availability of wood and the competitiveness of wood biomass compared to traditional fuel in terms of cost and performance [4-7].

\footnotetext{
Corresponding author: marina.clerico@polito.it
} 


\section{Literature}

Modern systems using wood biomass prove to be highly competitive compared with fossil fuels, especially as regards domestic heating. The amount of available wood biomass in Europe should ensure both the demands arising both from woodworking and energy purposes [8].

Wood boilers are emerging heating systems which are attractive for their reduction of $\mathrm{CO} 2$ emissions [9], but whose use may worsen local air quality conditions compared to traditional heating systems. Results $[10,11]$ show that the environmental performances of woodchip boilers at the local scale are not as good as those of natural gas boilers. However, the effect on local air quality of modern wood boilers is significantly lower than those of traditional stoves, since their emissions are significantly lower [12].

The wood transportation phase is significant in terms of pollutant emissions $[13,14]$. Small plants, which have needs that can be guaranteed by the surrounding territory, are becoming increasingly widespread, especially in areas where there are scattered forested areas (i.e., mountainous area). These plants, if technologically advanced, have low emissions but still need control to ensure that the impact on the territory is minimal and limited and to avoid the depletion of forest resources.

An environmentally sustainable use of this energy source mainly depends on a correct exploitation of the forest resources and on the atmospheric pollutants emissions control. Assuming that the timber consumption is suitably regulated by the forest management policies [15], the environmental impact of these systems is almost fully related to pollutant emissions in the atmosphere. These are due to two typologies of sources, at the local and regional scale. The former is due to the release of combustion products from the heating systems and the latter to the release of pollutant from vehicles transporting the wood. The choice of short supply chain implicates that the most significant emissions derives from the biomass burning process.

Especially in case of incomplete combustion, wood burning causes emissions of particulate matter (PM) [16, 17] and volatile organic compounds (VOCs). Other compounds that are very harmful for the human health and the environment, such as hydrochloric acid, dioxins and furans, may form in the event that the timber is contaminated by chlorine and in particular operating conditions of the heat generator. Numerous studies show that the combustion of biomass as a fuel is a significant source of PM [18] and gaseous emissions, such as VOCs [19] polycyclic aromatic hydrocarbons (PAHs) [20] and NOX [21]. The influence of the fuel characteristics on the quantity and composition of the emissions has been the subject of several studies [22, 23].

Several studies analyse the actual influence of these systems on air quality [24, 25], mainly focusing on the concentrations of PM, due to its well-known healtheffects [26]. The suitability of the adoption of these systems has to be carefully evaluated in regions where atmospheric PM concentrations are significant. This is the case of the Po Valley and of all neighbouring alpine valleys. The impact that such emissions may have on local air quality is not easy to assess for the different concurrent causes [27]; moreover, a method for the observation of local emissions of PM can influence local air concentration and help the identification of better solutions.

\section{Method}

The methodology was developed with the purpose of use both by forestry managers and local authorities. The forestry managers need a methodology to determine the best design choices, taking into account the distinctive features of each case influencing the identification of the best choices. Local authorities instead have to verify that implementing local wood biomass supply chain does not impact the environment, both in relation to the depletion of forest resources and to the emissions resulting from the biomass combustion.

The method consists of a simplified and adapted variant of the DPSIR (Drivers, Pressures, State, Impact and Response) method, already described in other publications [28, 29]. DPSIR is a framework for describing the interactions between society and the environment developed by the European Environmental Agency (EEA) [30]. The main variations to the standard method have been made to allow a quick application and easy identification of the main impacts even by people without a specific know-how. The ultimate users of the method are local authorities and plant managers. Through a division into elementary phases it is possible to identify the driver (i.e., the sources of impacts). To facilitate the identification of every possible source of impact, the drivers are classified into equipment, materials, work environment and work organisation. This classification and the division into elementary phases allow us, when the pressures on the environment are identified, to arrive at a unitary determination of the same, greatly facilitating the quantification. For some factors it is easier to arrive at a quantification (i.e., energy and raw materials used, waste produced, etc.), while others (i.e., noise, gas or dust emissions, etc.) need to consult the technical indications of manufacturers and designers. If this assessment is made at the design stage, only a qualitative estimate can be made, and different scenarios have to be considered.

The unitary determination of the pressures greatly facilitates their determination but makes it more difficult to determine the impacts on the surrounding environment. Different pressures could impact the same environmental component, and therefore there is the need to understand the interrelationship between the different pressures. To assess the impacts, a knowledge of the state of the territory is necessary. Different indicators to describe it are identified. To quantify them is important to analyse all the existing environmental data [31]. Only an in-depth knowledge of the actual state of the territory allows us to determine the subsequent impacts. Impacts are identified by determining the change in each identified environmental indicator 
determined by each pressure. First, impacts are qualitatively identified by assigning a red, yellow and green rating assessment to the identified impacts. This first analysis may be sufficient if the goal is to prioritise improvement interventions and identify critical issues. This assessment is often sufficient for local authorities and plant managers. If there are significant criticalities, a more deterministic estimate is necessary with the involvement of experts, but it is not the primary objective of the proposed method, being destined for a quick use. During the development and application phase of the method both measurements and modelling were used both for a quantitative evaluation and for a validation of the method to determine its accuracy.

\section{Results}

The method has been applied both to standard activities and the prototype plant [32]. The terms standard means activities which are well-known and spread among the companies working in the forest energy field. The methodology was applied in particular to the forest yards, to the fuel wood terminal and to the heat generators. The methodology was modified in order to adapt it to different characteristics and work environment. The obtained results allowed to determine what operational steps are the most critical with regard to the impact on the environment. The technical interventions and operational procedures to put in place to reduce these issues were also determined.

The aim of the method application to a prototype plant is to observe in particular its influence in the design phase and how it has to me modified in order to optimise this phase. The aim is to implement the analysed system before the construction phase as much as possible. Moreover, the application of the method can be seen as a starting point in the hypothesis of need of EC labelling in case of marketing of the prototype plant. The chosen project consisted in the construction of an integrated system for drying timber planks and energy recovery of wood by-products. The prototype was located in an alpine valley located in the north-west of Italy.

The methodology was applied both in the phase of plant design and plant implementation. In this way, modifications could be applied in all the design and construction phases. The most significant impacts are the alteration of the air quality and the modifications in the noise level and consequent annoyance for the people living nearby (Table 1). In order to determine if the method could satisfy all the objectives set at the beginning of the analysis, it has to be applied to assess the cumulative impacts caused by the whole forest energy chain.

Table 2 shows the main impacts for each phase of the supply chain and an assessment of the impacts through red, yellow and green ratio assessment. The table allows us to observe how a real assessment of the cumulative impacts is difficult through the only application of the method. Only a qualitative determination of the impacts is possible. A qualitative assessment, however, is not sufficient in the case of the implementation of different plants in the same territory. Therefore, the method is modified, integrating it with further analysis. However, the method allows us to determine that the most significant impacts are the use of wood resources and the air quality alteration. These aspects are very significant in the case of the spread of wood biomass heating systems. There would be, indeed, the need to determine the influence that a significant number of these systems could have on an area.

Table 1. Qualitative impacts of the prototype plant

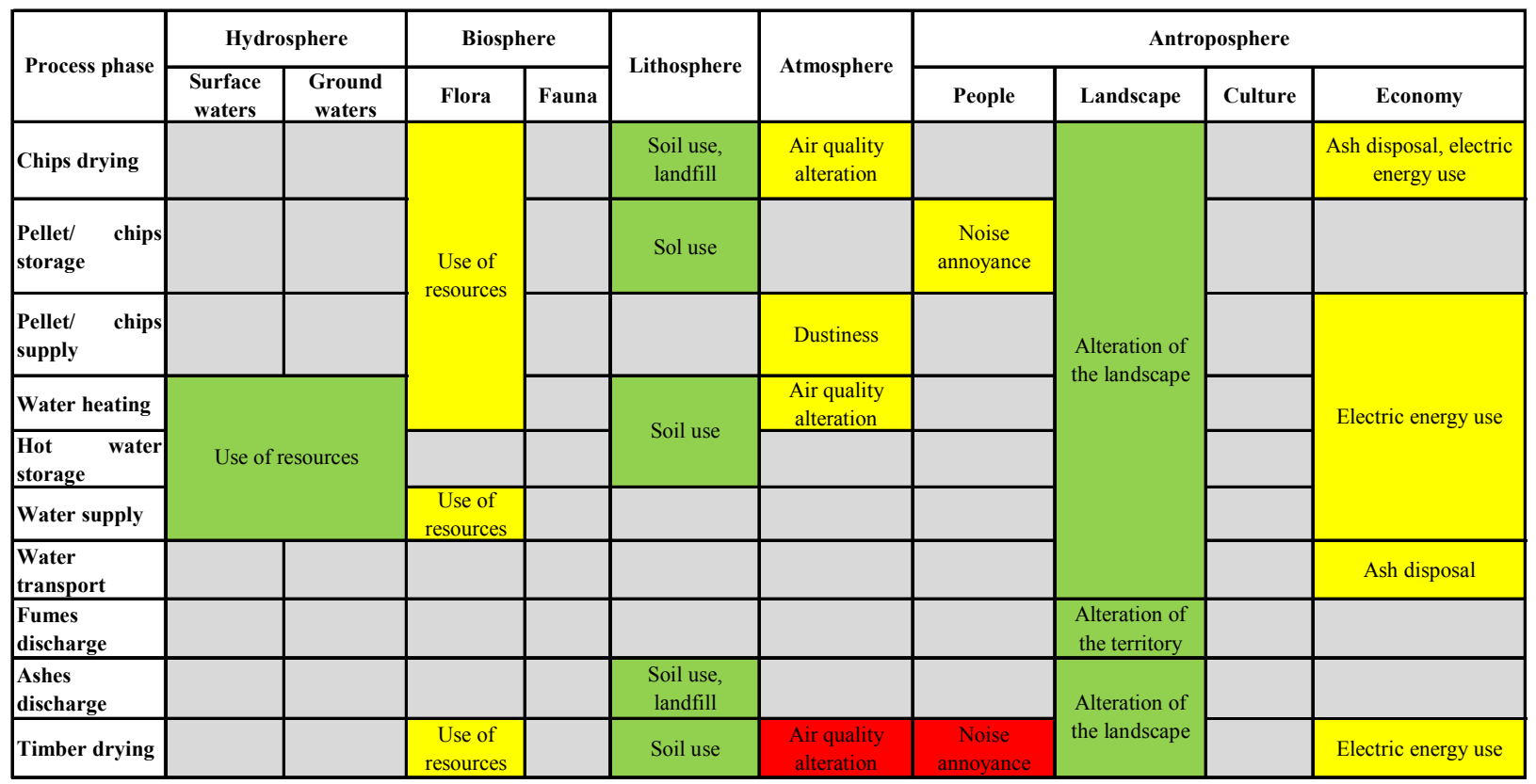


Table 2. Main cumulative impacts of the forest energy chain

\begin{tabular}{|c|c|c|c|c|c|c|c|c|c|c|}
\hline & \multicolumn{2}{|c|}{ Hydrosphere } & \multicolumn{2}{|c|}{ Biosphere } & \multirow{2}{*}{ Lithosphere } & \multirow{2}{*}{ Atmosphere } & \multicolumn{4}{|c|}{ Anthroposphere } \\
\hline & $\begin{array}{l}\text { Surface } \\
\text { waters }\end{array}$ & $\begin{array}{l}\text { Ground } \\
\text { waters }\end{array}$ & Flora & Fauna & & & People & Landscape & Culture & Economy \\
\hline $\begin{array}{l}\text { Timber } \\
\text { harvesting }\end{array}$ & $\begin{array}{c}\text { Alteration of } \\
\text { water flow }\end{array}$ & & $\begin{array}{c}\text { Flora } \\
\text { removing }\end{array}$ & $\begin{array}{c}\text { Wildlife } \\
\text { disturbance }\end{array}$ & Erosion & $\begin{array}{l}\text { Air quality } \\
\text { alteration }\end{array}$ & $\begin{array}{l}\text { Alteration of the } \\
\text { environmental } \\
\text { acoustic quality }\end{array}$ & $\begin{array}{l}\text { Alteration of } \\
\text { the landscape }\end{array}$ & & \\
\hline $\begin{array}{l}\text { Timber } \\
\text { transport }\end{array}$ & $\begin{array}{c}\text { Alteration of } \\
\text { water flow }\end{array}$ & & & & $\begin{array}{l}\text { Soil compaction } \\
\text { and modification } \\
\text { of slope stability }\end{array}$ & $\begin{array}{l}\text { Air quality } \\
\text { alteration }\end{array}$ & $\begin{array}{l}\text { Alteration of the } \\
\text { environmental } \\
\text { acoustic quality }\end{array}$ & & & \\
\hline $\begin{array}{l}\text { Timber } \\
\text { processing }\end{array}$ & & & & & & $\begin{array}{l}\text { Air quality } \\
\text { alteration }\end{array}$ & $\begin{array}{l}\text { Alteration of the } \\
\text { environmental } \\
\text { acoustic quality }\end{array}$ & & & \\
\hline $\begin{array}{l}\text { Timber } \\
\text { storage }\end{array}$ & & & & Soil use & & & & $\begin{array}{l}\text { Alteration of } \\
\text { the landscape }\end{array}$ & & \\
\hline $\begin{array}{l}\text { Timber } \\
\text { drying }\end{array}$ & & & & Soil use & & & & $\begin{array}{l}\text { Alteration of } \\
\text { the landscape }\end{array}$ & & \\
\hline $\begin{array}{l}\text { Energy } \\
\text { production }\end{array}$ & & & $\begin{array}{l}\text { Use of } \\
\text { wood } \\
\text { resources }\end{array}$ & Soil use & & $\begin{array}{l}\text { Air quality } \\
\text { alteration }\end{array}$ & & $\begin{array}{l}\text { Alteration of } \\
\text { the landscape }\end{array}$ & & $\begin{array}{l}\text { Use of resources } \\
\text { for energy } \\
\text { distribution }\end{array}$ \\
\hline
\end{tabular}

\section{Discussion}

The validation of the environmental impact assessment method was made by carrying out the measurements for the most significant hazard factors. In this particular case, they were PM emissions and noise. Given the position of the plant, without residential areas nearby, noise was considered negligible.

Measurements to quantify PM emissions were therefore carried out in the plant chimney and externally near the source. The carried out monitoring was aimed at the characterisation of the prototype plant object of study as an emissive source relative to particulate matter.

The four emissions tests at the chimney showed results within the limit values set by the technical standards [33].

In order to assess airborne pollutants emissions, the prototype plant has been considered as an emissive source relative to particulate matter, with PM10 as indicator. The European PM10 limit values for life environments [34] are considered only indicative since they represent concentration limits at the receptor of damage. The standard methodology [35] was applied for measuring the concentration of particulate matter close to the emissive sources (near field). To assess how a source of emissions could influence a territory, long-term sampling monitoring near the receptors point should be designed in order to observe the modification in air quality. The aim of the carried out measurements is to assess the pressures on the territory deriving by the sources.

The monitoring results show an overall emissive framework compatible with the territory. With the exception of few values, considering also the presence of outliers and the dirty road near the measuring point, the PM10 monitoring campaign has not evidenced a clear impact from the prototype plant at the testing location.

The results were compatible with the qualitative assessment done through the application of the method.
Indeed the emissions deriving from this kind of system are not significant in a case by case assessment, but the outcomes confirm the need to assess the cumulative impacts in the hypothesis of different plants in the same territory. The best way to assess them is the modelling of the ground concentration though dispersion model. This issue has been considered in other publications $[10,11]$. The results have shown a perceivable reduction of PM concentration if the modern application of a wood heating system was coupled with another renewable source (i.e., photovoltaic system) and improved building energy performance.

\section{Conclusions}

The need to deal quickly and punctually with the environmental unsustainability of the various economic sectors has led to the need to quickly assess whether the proposed solutions are actually improvements, not only in terms of local impact but also on a larger scale.

The aim of the research was to identify a methodology for expeditious analysis. The method of analysis was directed to two different entities-the operators of the forest wood energy sector and the local authorities. Therefore, it had to ensure an expeditious and comprehensive study of the aspects considered and, at the same time, the sustainability of this solution with a view of the territorial spreading.

The main issue met during the development of the methodology was its need to be suitable to often very different workplaces and technological alternatives. For this reason, once the methodology was drafted, it was applied to case studies belonging to different moments of the supply chain to validate it by taking into account the highest number of possible typical characteristics. The method has therefore been implemented according to the obtained results and the difficulties experienced.

The applied and validated methodology fit adequately to the different specificities of the identified 
case study and made it possible to identify the criticalities case by case.

The validation of the method, through the application of standardised methodologies, shows how the developed methodology can be consistent with the aims of the research and suitable according to the considered points of view.

While in the application to a single case, the methodology resulted as compatible with the aims of the research; the need to implement dedicated tools to assess the cumulative impacts of different plants as a model for the dispersions of pollutants has emerged from the validation. Therefore, in the case of the adoption of this design hypothesis by the local authorities, the methodology should include the integration constituted by dedicated measurements, evaluation of resources availability and, eventually, pollutant dispersion models.

\section{References}

1. European Parliament; Council of the European Union Directive 2014/52/EU of the European Parliament and of the Council of 16 April 2014 amending Directive 2011/92/EU on the assessment of the effects of certain public and private projects on the environment. Off. J. Eur. Union, 124, 1-18 (2014).

2. European Commission SMEs and the Environment in the European Union (2010).

3. Hasle, P.; Limborg, H.J. A review of the literature on preventive occupational health and safety activities in small enterprises. Ind. Health, 44, 612 (2006).

4. Verma, V.K.; Bram, S.; De Ruyck, J. Small scale biomass heating systems: Standards, quality labelling and market driving factors - An EU outlook. Biomass and Bioenergy, 33, 1393-1402 (2009).

5. Goryunov, A.; Goryunova, N.; Ogunlana, A.; Manenti, F. Production of energy from biomass: near or distan future prospects? Chem. Eng. Trans, 52 (2016).

6. Stolarski, M.J.; Krzyżaniak, M.; Warmiński, K.; Śnieg, M. Energy, economic and environmental assessment of heating a family house with biomass. Energy Build, 66, 395-404 (2013).

7. Klavs, G.; Kudrenickis, I.; Kundzina, A. Analysis of Competitiveness and Support Instruments for Heat and Electricity Production from Wood Biomass in Latvia. Latv. J. Phys. Tech. Sci, 49, 313 (2012).

8. Smeets, E.M.W.; Faaij, A.P.C. Bioenergy potentials from forestry in 2050. Clim. Change, 81, 353-390 (2006).

9. Madlener, R.; Koller, M. Economic and CO2 mitigation impacts of promoting biomass heating systems: An input-output study for Vorarlberg, Austria. Energy Policy, 35, 6021-6035 (2007).

10. Pognant, F.; Bo, M.; Nguyen Chi, V.; Salizzoni, P.; Clerico, M. Modelling and evaluation of emission scenarios deriving from wood biomass boilers in alpine valley. Proceedings of the HARMO 2017 - 18th International Conference on Harmonisation within Atmospheric Dispersion Modelling for Regulatory Purposes, 2017; (2017).

11. Pognant, F.; Bo, M.; Nguyen, C.V.; Salizzoni, P.; Clerico, M. Design, Modelling and Assessment of Emission Scenarios Resulting from a Network of Wood Biomass Boilers. Environ. Model. Assess, 23, 157-164 (2018).

12. Vicente, E.D.; Alves, C.A. An overview of particulate emissions from residential biomass combustion. Atmos. Res, 199, 159-185 (2018).

13. Handler, R.M.; Shonnard, D.R.; Lautala, P.; Abbas, D.; Srivastava, A. Environmental impacts of roundwood supply chain options in Michigan: life-cycle assessment of harvest and transport stages. J. Clean. Prod. 2014, 76, 64-73.

14. Neri, E.; Cespi, D.; Setti, L.; Gombi, E.; Bernardi, E.; Vassura, I.; Passarini, F.; Neri, E.; Cespi, D.; Setti, L.; et al. Biomass Residues to Renewable Energy: A Life Cycle Perspective Applied at a Local Scale. Energies, 9, 922 (2016).

15. Mendoza, G.A.; Prabhu, R. Development of a Methodology for Selecting Criteria and Indicators of Sustainable Forest Management: A Case Study on Participatory Assessment. Environ. Manage, 26, 659-673 (2000).

16. Tissari, J.; Lyyränen, J.; Hytönen, K.; Sippula, O.; Tapper, U.; Frey, A.; Saarnio, K.; Pennanen, A.S.; Hillamo, R.; Salonen, R.O.; et al. Fine particle and gaseous emissions from normal and smouldering wood combustion in a conventional masonry heater. Atmos. Environ, 42, 7862-7873 (2008).

17. Tissari, J.; Hytönen, K.; Lyyränen, J.; Jokiniemi, J. A novel field measurement method for determining fine particle and gas emissions from residential wood combustion. Atmos. Environ, 41, 8330-8344 (2007).

18. Meyer, N.K. Particulate, black carbon and organic emissions from small-scale residential wood combustion appliances in Switzerland. Biomass and Bioenergy, 36, 31-42 (2012).

19. Arshadi, M.; Geladi, P.; Gref, R.; Fjällström, P. Emission of Volatile Aldehydes and Ketones from Wood Pellets under Controlled Conditions. Ann. Occup. Hyg, 53, 797-805 (2009).

20. Bruschweiler, E.D.; Danuser, B.; Cong, K.H.; Wild, P.; Schupfer, P.; Vernez, D.; boiteux, P.; Hopf, N.B. Generation of polycyclic aromatic hydrocarbons (PAHs) during woodworking operations. Cancer Epidemiol. Prev, 2, 148 (2012).

21. Bugge, M.; Skreiberg, Ø.; Haugen, N.E.L.; Carlsson, P.; Seljeskog, M. Predicting NOx Emissions from Wood Stoves using Detailed Chemistry and Computational Fluid Dynamics. Energy Procedia, 75, 1740-1745 (2015).

22. Hays, M.D.; Smith, N.D.; Kinsey, J.; Dong, Y.; Kariher, P. Polycyclic aromatic hydrocarbon size distributions in aerosols from appliances of residential wood combustion as determined by 
direct thermal desorption-GC/MS. J. Aerosol Sci, 34, 1061-1084 (2003).

23. Calvo, A.I.; Tarelho, L.A.C.; Alves, C.A.; Duarte, M.; Nunes, T. Characterization of operating conditions of two residential wood combustion appliances. Fuel Process. Technol, 126, 222-232 (2014).

24. Caseiro, A.; Bauer, H.; Schmidl, C.; Pio, C.A.; Puxbaum, H. Wood burning impact on PM10 in three Austrian regions. Atmos. Environ, 43, 21862195 (2009).

25. Favez, O.; Cachier, H.; Sciare, J.; Sarda-Estève, R.; Martinon, L. Evidence for a significant contribution of wood burning aerosols to PM2.5 during the winter season in Paris, France. Atmos. Environ, 43, 3640-3644 (2009).

26. Kim, K.-H.; Kabir, E.; Kabir, S. A review on the human health impact of airborne particulate matter. Environ. Int, 74, 136-143 (2015).

27. Gerasopoulos, E.; Kouvarakis, G.; Babasakalis, P.; Vrekoussis, M.; Putaud, J.-P.; Mihalopoulos, $\mathrm{N}$. Origin and variability of particulate matter (PM10) mass concentrations over the Eastern Mediterranean. Atmos. Environ, 40, 4679-4690 (2006)

28. Bo, M.; Clerico, M.; Pognant, F. Application of risk analysis to improve environmental sustainability of forest yards in wood-energy chain. Int. Sci. Journal, J. Environ. Sci, 2015, 125-130 (2015).

29. Bo, M.; Fargione, P.; Maida, L.; Pognant, F. Occupational Safety and Health and Environmental Safety criticalities depending on geo-economic areas: a focus on mining and quarrying activities. Proceedings of the Prevention of accidents at work; ; 8 (2017).

30. EEA Environmental indicators: Typology and overview (1999).

31. Bo, M.; Clerico, M.; Pognant, F. Analytical method for environmental data representativeness of a territory. Geoing. Ambient. e Mineraria, 144 (2015).

32. Pognant, F. Environmental sustainability and Occupational Safety and Health in the forest energy chain for small generation systems. (2019).

33. EN 303-5:2012 Heating boilers-Part 5: Heating boilers for solid fuels, manually and automatically stoked, nominal heat output of up to $500 \mathrm{~kW}$ Terminology, requirements, testing and marking (2012).

34. European Commission Directive 2008/50/EC of the European Parliament and of the Council of 21 May 2007 on ambient air quality and cleaner air for Europe (2008).

35. CSN EN 12341, E.S. CSN EN 12341 - Ambient air - Standard gravimetric measurement method for the determination of the PM10 or PM2,5 mass concentration of suspended particulate (2014). 